\title{
Health system redesign following sexual violence during the genocide in Rwanda
}

\author{
Glorieuse Uwizeye $(\mathbb{D} \cdot$ Bandy X. Lee $\cdot$ Thilo Kroll
}

Received: 13 December 2015/Accepted: 9 August 2016/Published online: 9 October 2016

(c) Swiss School of Public Health (SSPH+) 2016

Sexual violence directed as a weapon against populations during armed conflict and genocide has a systemic, longterm impact on the institutions and social cohesion of a country (Reid-Cunningham 2008). There may be great variation in the form and magnitude of violence, who is targeted, and whether such violence is the result of a specific tactic and plan. Local research for local interventions is required but so is research to tackle violence on a global scale (Krug et al. 2002). Experiences from Rwanda and other countries, where rape was used systematically against women, showed long-term physical and psychosocial trauma at the individual, family, and at societal levels (Eytan et al. 2015).

In 1994, the public health and socioeconomic functioning of Rwanda's entire population collapsed as a consequence of the sexual violence and genocide-related atrocities. In Rwanda, the sexual violence against Tutsi women was marked by close proximity: perpetrators were and are neighbors, colleagues, and family members. Women who were raped were not only dealing with the impact on their physical and mental health but also facing their perpetrators or those who helped them. Furthermore,

This Editorial is part of the special issue "Violence and Health: Implications of the 2030 Agenda for South-North Collaboration",

G. Uwizeye $(\bowtie)$

Nursing Advisor Ministry of Health, Kigali, Rwanda

e-mail: uglorieuse@gmail.com

B. X. Lee

Yale University, School of Medicine, Law and Psychiatry

Division, New Haven, CT, USA

T. Kroll

UCD School of Nursing, Midwifery and Health Systems, Dublin, Ireland the challenges are not confined to the women's generation, but their children may struggle with posttraumatic stress disorder (PTSD) symptoms, behavioral and psychological problems, and educational attainment deficits (Roth et al. 2014). They may face social marginalization from being considered 'the product' and reminder of rape, and may experience rejection by families and neighbors, as with their mothers.

Tackling these complex consequences requires a comprehensive, multi-sectorial design of sensitive, timely, affordable, and effective health and social support structures. Rwanda began to rebuild its health, education, and social care systems over 20 years and showed that the redesign process needs to go hand in hand with drawing on local expertise and working across professional disciplines and governmental departments. The Government of Rwanda has made substantial strides in rebuilding a healthcare system that has evolved from donor- or global North-led interventions into local initiatives that invite North-South collaboration under the leadership of government. In this way, the government can build a system that meets primary, local needs, including better care for the survivors. The legacy of the Rwandan genocide shows that survivors of sexual violence and/or rape and their family members require multi-layered and integrated support, including mental healthcare provision, access to primary and specialist care, educational and career development advice, and legal protection. Other examples include the Alaskan Nuka System of Care, which is a bottom-up design and a communitycontrolled healthcare system, to address the physical and mental health of the community (Gottlieb 2013).

Through this bottom-up approach, we can earn public trust and build a system that tailors to specific local needs. Rwanda has made tremendous efforts and progress in restoring security, promoting reconciliation, and achieving 
justice through Gacaca courts, the traditional justice system where a community and its elected leaders known for their integrity and wisdom gather to judge genocide cases in their community. It has also initiated a fund for genocide survivors to meet basic needs such as housing, primary medical care, and education.

National reconciliation as well as institutional redesign requires sensitive leadership, motivated cross-sectorial partnerships, and creative human resources to tackle the complex aftermath of sexual violence and its health and socioeconomic impact. Finally, this process needs to be accompanied by the design and implementation of reliable data collection and learning systems infrastructure to monitor progress and efficacy of the integrated and interconnected systems (Grossmann et al. 2011). These data can, in turn, inform South-North collaborations for violence reduction at a global scale.

In conclusion, sexual violence directed at populations during armed conflict as a weapon of genocide has a profound and systemic, long-term impact on all levels of society. The rebuilding of efficacious and trusted institutions requires a process of bottom-up co-creation and integration of social service systems with accompanying data monitoring that can continue to help enhance interventions.
Acknowledgments The authors would like to gratefully acknowledge Grace Lee for her help in the initial conceptualization of this editorial.

\section{References}

Eytan A, Munyandamutsa N, Nkubamugisha PM, Gex-Fabry M (2015) Long-term mental health outcome in post-conflict settings: similarities and differences between Kosovo and Rwanda. Int J Soc Psychiatry 61(4):363-372. doi:10.1177/ 0020764014547062

Gottlieb K (2013) The Nuka system of care: improving health through ownership and relationships. Int J Circumpolar Health. doi:10. 3402/ijch.v72i0.21118

Grossmann C, Goolsby WA, Olsen LA, McGinnis JM (2011) Engineering a learning healthcare system: a look at the future. In: Workshop summary. Roundtable on value and science-driven healthcare. The learning health systems series. Institute of Medicine (IOM), Washington, DC

Krug EG, Dahlberg LL, Mercy JA, Zwi AB, Lozano R (2002) World report on violence and health. World Health Organization, Geneva. http://apps.who.int/iris/bitstream/10665/42495/1/ 9241545615_eng.pdf. Accessed 5 Sept 2016

Reid-Cunningham AR (2008) Rape as a weapon of genocide. Genocide Stud Prev 3(3):279-296. doi:10.3138/gsp.3.3.279

Roth M, Neuner F, Elbert T (2014) Transgenerational consequences of PTSD: risk factors for the mental health of children whose mothers have been exposed to the Rwandan genocide. Int $\mathbf{J}$ Mental Health Syst 8:12. doi:10.1186/1752-4458-8-12 